\section{Heroínas y malvadas: la construcción de la imagen femenina en Penny Dreadfull (2014-2016), de John Logan}

Mónica Gruber *

Resumen: Los años '50 saludaron al cine como el rey del entretenimiento. Asimismo, a lo largo del siglo pasado, muchas voces se alzaron vaticinando su muerte. Sin embargo, lejos de desaparecer, las pantallas se han multiplicado exponencialmente: cine, televisión, celulares y tablets producen y reproducen la realidad que nos rodea. Pantallas de todo tipo: de cristal líquido, planas, táctiles, gráficas, pequeñas y gigantes. Se trata del apogeo de la "pantalla global", tal como afirman Lipovetsky y Serroy (2009). Nos hallamos, indudablemente, sumergidos en el mundo de la imagen.

La velocidad, el cambio y la fragmentación caracterizan nuestro tiempo. Satisfacer la demanda del ávido público consumidor de productos de entretenimiento se torna el mayor desafío del presente. De este modo, las series producidas para televisión y los diversos sistemas streaming pugnan por convertirse en los emperadores indiscutibles. Podemos afirmar, sin temor a equivocarnos, que las series son al espectador mediático lo que otrora fue el cine de la edad de oro a sus audiencias. De este modo, actores, productores y directores cinematográficos se han visto tentados a incorporarse en este campo que se halla en franca expansión. Desde Internet a las diversas plataformas -Netflix, Qubit TV y la autóctona Cine.Ar, entre otras- pasando por los canales con paquetes premium, la oferta se multiplica ofreciendo los más diversos productos para los paladares más exigentes.

Asistimos en este momento a una época de grandes cambios: los movimientos feministas que ayudan a repensar el rol de la mujer, así como las relaciones entre sexos en el pasado y el presente, proyectándolos de cara al futuro. La globalización expande, por medio de las comunicaciones, los alcances de dichos cambios a todos los sectores del planeta. Y dada la profusión de productos televisuales, no es de extrañar que todas estas transformaciones se reflejen en los medios de comunicación.

Las series como todas las demás producciones no quedan al margen. Todas y cada una presentan temas que inquietan: las relaciones entre los sexos, la independencia de la mujer, los cuerpos -trans, ciber, post humanos- entre otros, nutren los diversos relatos.

Este trabajo se propone analizar la construcción de la imagen femenina en la serie televisiva: Penny Dreadfull (2014-2016), creada por John Logan. Esta coproducción estadounidense-británica ha explorado el vampirismo, lo demoníaco, la licantropía, la vida artificial y la eterna juventud. La primera temporada de la serie versa sobre la búsqueda de Mina, la desaparecida hija de Sir Malcom Murray. Para ello contará con la ayuda de Vanessa Ives, amiga de la niñez de su retoño. Ayudados por Ethan Chandler, el fiel sirviente africano Sembene y Víctor Frankenstein. Este último dará vida -artificial- a una progenie monstruosa: Proteus, de vida efímera; Calibán, que ante la falta de amor de su hacedor le exigirá una compañera y Lily, ¿una suerte de Lilith rediviva? La tercera temporada contará con la 
presencia de Drácula, quien intentará coronar a Vanessa como la Madre de todos los males. De este modo, heroínas y malvadas dan vida a inquietantes féminas.

Nos interesa analizar los diversos roles femeninos que encarnan un equilibrio polarizado entre heroínas y malvadas, además, transitar el camino que recorren para reflexionar acerca de sus características, cómo se construye o de-construye el personaje femenino para averiguar si la heroína y la malvada conviven en el interior de un mismo personaje o si se trata de personajes diferentes, pero por sobre todo, si la visión sobre las mujeres que aparece en la serie corresponde a la de la época victoriana en la cual se halla ambientado el relato, o si refleja elementos de nuestro presente distanciados temporalmente. Es así que suponemos poder leer nuestro presente a partir de dicha producción serial.

Palabras clave: Imagen femenina - Construcción - Heroína - Malvada - Serie - Personaje - Evolución - Cambios - Estereotipos - Vida artificial

[Resúmenes en inglés y portugués en las páginas 143 - 145]

${ }^{(*)}$ Licenciada y Profesora en Artes (UBA). Es Profesora Adjunta, a cargo de La Literatura en las Artes Combinadas I / Literatura en las Artes Audiovisuales en Diseño de Imagen y Sonido (UBA) y Jefa de Trabajos Prácticos en la FFyL (UBA). Profesora de Diseño Audiovisual II en la UP y docente del Museo Social Argentino y de la UTN. Codirectora a Cargo del Proyecto PIA de Investigación Los mitos en las artes audiovisuales: pervivencia y resemantización (FADU-UBA). Ha participado como ponente en Congresos Internacionales y Nacionales. Fue colaboradora de la revista Tipográfica. Tiene publicados capítulos en volúmenes de la FADU, de la Academia Nacional y en Cuadernos de Diseño y Comunicación (UP).

\section{Introducción}

Un anclaje verbal nos sitúa en Londres, en el año 1891. Es de noche, una mujer y una niña pequeña comparten una cama en una habitación humilde. Vemos que son pobres también por los enseres y la indumentaria. La niña duerme. La mujer intenta por todos los medios permanecer en la cama. Hace frío. Finalmente decide dirigirse al sanitario. Se desplaza por un pasillo oscuro. Ya dentro, un ruido llama su atención. La ventana se quiebra en mil pedazos al tiempo que la oímos gritar. La niña se despierta y se dirige hacia el sitio donde se encuentra su madre; vacila, tiene miedo. Al ingresar todo parece acelerarse, el grito de espanto y algo que la mata. Al día siguiente, las fuerzas policiales no dejan de sorprenderse. El fotógrafo forense y la policía registran los restos de los cuerpos despedazados de la mujer y la pequeña. La sangre empapa las paredes y el suelo. Si los primeros minutos de cada film le suministran al espectador las claves y el verosímil para descifrar la intriga, no menos cierto es que este inicio supone ya algunas pistas, algo anómalo ha sucedido: fuerzas misteriosas - ¿malignas?- se han cobrado dos víctimas. 
¿Serán las mismas fuerzas que han secuestrado a Mina, la hija de Sir Malcom Murray, el explorador del continente africano? En esta dirección orientarán su búsqueda los protagonistas de la serie: el padre de la joven y Miss Vanessa Ives, la amiga de su retoño. En la peligrosa aventura contarán con la ayuda de Sembene, el sirviente africano de los Murray e irán contratando aliados en función de sus habilidades poco comunes: Ethan Chandler, un diestro pistolero norteamericano, de oscuro pasado y el doctor Víctor Frankenstein, un científico apasionado por los secretos de la vida y de la muerte.

La primera temporada de la serie británico-norteamericana Penny Dreadful ${ }^{1}$ (2014-2016), creada por John Logan, se desarrolla en una Londres laberíntica donde la búsqueda por parte de esta suerte de cofradía llegará a adquirir los ribetes de una katábasis ${ }^{2}$ para rescatar a la muchacha antes de que sea demasiado tarde. Demonios y vampiros completarán el cuadro de figuras monstruosas que habitan entre las sombras y contra las que deberán luchar. Paralelamente, Víctor manipulará cadáveres y jugará a ser Dios y, del mismo modo que en el relato de Mary Shelley, dará vida artificial a una progenie monstruosa ${ }^{3}$ : Proteus, un ser noble, que pierde su vida a manos de su hermano mayor; Calibán /John Clare, el asesino primogénito -reactualizando de este modo el mito de Caín y Abel- y, por último Lily, la fémina del grupo monstruoso.

Hará su aparición también Dorian Gray, antiguo empleador de Brona, la prostituta fallecida cuyo cuerpo y mente han servido de materia prima a la creación de Lily, ahora convertido en su aliado y amante.

La segunda temporada, verá por momentos su desplazamiento hacia zonas rurales que funcionan como espacios reservados para la hechicería y lo sobrenatural. La brujería, la posesión demoníaca y lo sobrenatural entrarán en escena. Descubriremos que el secuestro de Mina ha sido solo una excusa, ya que el verdadero blanco del Mal es Vanessa. Adquirirá también desarrollo el tópico de la licantropía.

La temporada final alternará entre Gran Bretaña y Estados Unidos. Será el momento de la aparición del Conde Drácula, quien buscará por todos los medios coronar a Vanessa como la Madre de todos los Males. Con algunas bajas y nuevos aliados, será este nuevo grupo el que lleve adelante la batalla final en la que las leyendas indígenas y el papel privilegiado de uno de los integrantes, los colocará en condiciones de superioridad para luchar con el propósito de salvar a la humanidad de perecer en la noche de los tiempos.

Recientemente la empresa Showtime de televisión premium, anunció el inicio del rodaje de Penny Dreadful: City of Angels, descendiente espiritual de la anterior. Ambientada en 1930 promete encarnar el espíritu de las tres temporadas anteriores. Se desconoce con precisión la fecha de su estreno.

Nos proponemos en este caso lucubrar acerca de la construcción de algunos personajes femeninos, su conformación y la difícil delimitación que percibimos entre heroínas y villanas.

\section{La intrigante Miss Ives}

Se trata solo de bosquejar algunas líneas argumentales, en realidad en muchos casos desplegaremos de forma lineal partes de la historia que nos han sido develadas a lo largo de las diversas temporadas a través de recuerdos, relatos y cartas que cobran presencia en los flashbacks. 
Eva Green encarna a Vanessa, un personaje cautivador e inquietante, etérea por momentos y por otros una suerte de femme fatale, pero que siempre es capaz de dar su vida por los demás. No obstante, podemos pensar en una heroína pura y casta, y no sería este el caso. La joven se maneja entre los límites de la luz y la oscuridad. Mr. Lyle, el especialista en escritura egipcia, al descifrar unos jeroglíficos desconocidos que supuestamente constituyen un fragmento perdido del Libro de los Muertos, revelará que el demonio la persigue, pero le recomienda a Murray no revelárselo a la joven ya que: "Después de todo ¿quién desea saber que el demonio lo persigue?"

A medida que nos adentramos en el visionado de los capítulos, notamos en los primeros que hay una tensión manifiesta entre Sir Malcom y Vanessa. Poco a poco, irán apareciendo pequeños fragmentos que develarán los motivos. ¿Puede el hombre ser tan insensible como para utilizarla como carnada? ¿A qué se debe ese menosprecio que observa hacia la joven? ¿No es acaso la compañera de su hija y lo ayuda en la búsqueda? La revelación llegará a la mitad de la primera temporada. La carta que Vanessa escribe a su amiga ausente nos permitirá reconstruir un pasado doloroso. Un flashback nos mostrará que las jóvenes eran como hermanas, pasaban sus días juntas ya que, a la sazón, eran vecinas. Sus casas lindantes, mantenían la puerta de separación de las mansiones abierta, lo que les permitían un contacto permanente. La amistad de las familias se replicaba también en los progenitores y la ausencia del explorador, por largos períodos de tiempo, era contrarrestada por la compañía de la familia y los vecinos/amigos.

Luego del regreso de Sir Murray, Vanessa descubrirá el adulterio de éste con su madre. Los sorprenderá en el laberinto del jardín. La niña guardará silencio al respecto. Sin embargo, le confesará, años más tarde, en la carta a su amiga que esa noche la cambió para siempre. Peter, el hermano de Mina, rechaza a la muchacha quien le ha robado un beso. Humillada y avergonzada, la joven relata: "Traté de rezar esa noche pero Dios no me contestó, pero otro sí lo hizo". Como espectadores oímos una voz masculina profunda y aterrorizante que le responde: "Pronto niña, jugaremos un juego".

Esa noche, las muchachas comparten la habitación. Es la noche previa a la boda. La música crea un clima de suspenso acorde al marco de la tormenta eléctrica que se cierne sobre el lugar. Mina duerme. Su amiga se desplaza en camisón a través de la casa hasta toparse con el Capitán Branson, el prometido de su amiga. Intrigante le propone al joven: “ $¿$ Quieres ver algo interesante?" Ella lo lleva al cuarto de taxidermia. Allí le revela la actividad ignota de su novia y le muestra los animales disecados. Mina ha trabajado con animales pequeños como ardillas; ella le muestra el suyo, Ariel, un ave de rapiña con las alas desplegadas en posición de ataque. La música acompaña el lento ritmo de la escena. El diálogo que mantienen es banal, acerca de los animales. La oscuridad baña el ambiente se ve interrumpida por momentos por la luz de los rayos que ingresa por los ventanales. La tensión sexual se va incrementando. Inevitablemente el encuentro tendrá lugar, sobre la mesa de trabajo, en medio de los animales embalsamados, mudos testigos de lo que sucede. La violencia se apodera de la escena, para dar lugar casi a un cliché: la joven se recuesta, y al voltear la cabeza, la luz ilumina a Mina, presenciando el triste espectáculo.

Las familias rompen toda forma de contacto, la puerta cerrada entre las mansiones lindantes, manifiesta en imágenes esta decisión. Mina se va de la casa con rumbo incierto y Vanessa empieza a ser consumida por una enfermedad aparentemente desconocida. 
Poseída por el demonio, la joven se debate entre la vida y la muerte. Sin embargo, los médicos y psiquiatras diagnostican una enfermedad mental. Sedantes, camisa de fuerza, aislamiento y terapia hídrica forman parte de su tratamiento en la clínica psiquiátrica del Dr. Banning. La muchacha recordará años más tarde, el diálogo sostenido con su celador:

Hombre: No es tortura lo que le hacen, es ciencia. La ciencia la sanará.

Vanessa: Es para volverme normal, como las otras mujeres que conoce. Sumisa, obediente... Una subalterna en la máquina social. ¡Y nada más!

Corriéndonos del argumento ficcional, recordemos que el uso de terapia hídrica se había tornado moneda corriente tal como refiere el filósofo francés M. Foucault en su Historia de la locura en la época clásica:

[...] A partir del fin del siglo XVII, la curación por medio de baños vuelve a ocupar un lugar importante entre las terapéuticas de la locura. Cuando Doublet redacta su Instruction, poco antes de la Revolución, prescribe, para las cuatro formas patológicas que él reconoce (frenesí, manía, melancolía, imbecilidad), el empleo regular de los baños, agregando para las dos primeras, el uso de duchas frías. $(1998$, p. 111)

Se buscaba tranquilizar la mente a través del cuerpo, enarbolando la bandera de los avances científicos. El cuerpo era sometido a terribles tormentos. Los progresos del siglo XX no serían mejores: electroshocks, drogas, terapia hídrica y lobotomías seguirían en la senda abierta en los siglos anteriores. El cuerpo del loco se tornó de este modo en un campo de batalla en el cual se experimentaron los más terribles tratamientos.

Lo que muestra la serie no expone ninguna práctica que no fuese moneda corriente en los asilos para locos de la época. La joven será sometida a una trepanación, regresando a su hogar desconectada del mundo que la rodea. Inmóvil, con la mirada fija, consumida y apagada. ¿Será este su fin? Su fuerza de voluntad la hará resistir y se recuperará muy lentamente.

En base a los resortes de la amistad traicionada y sus causas, tomamos consciencia por un lado los motivos por los cuales Malcom guarda cierta hostilidad hacia la muchacha y, por otro, por qué ella siente culpa por lo sucedido.

En tres ocasiones tratará de hallar amor y un sitio junto a una figura masculina que la atrae. Durante la primera temporada, junto a Dorian Gray el erotismo se hará presente, pero al intentar llevar adelante su relación, Vannessa escuchará al mismísimo demonio, por lo cual el encuentro sexual quedará trunco. Durante la segunda temporada, será Ethan su compañero, la relación entre ambos se irá tornando cada vez más afectuosa, el amor los sobrevuela, pero ella lo rechaza argumentando que es imposible tal encuentro: "Porque somos los dos muy peligrosos".

La temporada final será la ocasión en que Vanessa, deslumbrada por el Dr. Alexander Sweet, Director de Estudios Zoológicos del Museo de Ciencias Naturales de Londres, se verá seducida por éste. Muy a su pesar descubrirá que en realidad se trata de Drácula, quien buscará unirse a ella para coronarla como la reina de la oscuridad: la Madre de todos los Males. 
Consideramos que algunos de los momentos más logrados de la serie los constituyen las conversaciones que sostiene con John Clare (Calibán), en la parte pobre de la ciudad durante una epidemia de cólera. Ella hermosa. Él monstruoso. Entablan una suerte de amistad que nos recuerda a La bella y la bestia. No podemos dejar de señalar la profundidad de los diálogos que sostienen: razonan sobre la vida, sobre diversos aspectos filosóficos y éticos y, asimismo, disfrutan recordando pasajes de obras de Wordsworth ${ }^{4}$ y de Blake W $^{5}$ Clare se siente avergonzado por su aspecto, sin embargo, será la muchacha quien sabrá ver lo que hay en el fondo de su corazón, más allá de su fealdad. Tal como ella le hará saber: "Tiene ojos hermosos".

Miss Ives ha traicionado a su amiga la noche previa a su boda, pero lo ha hecho presa de la posesión demoníaca. En igual circunstancia, luego de la sesión de espiritismo en la cual aterroriza a los asistentes a la fiesta de Mr. Lyle, Vanessa saciará su apetito sexual desenfrenado con un transeúnte, en las calles de una Londres oscura y tormentosa.

Un dato interesante lo aporta la presencia de una psiquiatra, a quien recurrirá en busca de ayuda. Patti LuPone, que encarna a la Dra. Seward es la misma actriz, que diese vida a Joan Clayton, la gran protectora y maestra de Vannessa y quien le enseñase a controlar sus poderes. De ella provienen todos sus conocimientos de brujería, con ella ha despertado y aprendido a controlar las oscuras fuerzas, pero también ha sido testigo de su muerte: quemada por la muchedumbre en la hoguera, por brujería. Vanessa recuperará sus conocimientos al volver al páramo para vengar la muerte de su mentora. En una ceremonia secreta y, pese a la advertencia de Ethan de no traspasar ese umbral, la joven invocará al mal para asesinar al responsable de la mencionada quema.

Salvo por la antigua amistad, la joven no tiene relación con otras mujeres, se mueve en un mundo donde la rodean personajes masculinos. Con el tiempo y, dadas todas las terribles pruebas que atraviesa, la protección de Sir Malcom se intensificará. La segunda temporada mostrará a la joven consumida por la posesión demoníaca. Sus amigos no la abandonarán y ella resistirá por todos los medios hasta poder recuperarse e intentar salvar su alma. Será Ethan quien gane su corazón. Creemos que la permanente amenaza de las fuerzas del mal representan el sino trágico de esta mujer. Este personaje femenino presenta una gran fortaleza: incapaz de sucumbir ante el mal, resiste aún a costa de su cuerpo consumido. Vanessa le arrancará a Ethan el juramento de que, de ser necesario, él la matará si ello sirve para evitar que el demonio se apodere de su alma.

No podemos dejar de mencionar que Ethan jugará un papel decisivo ya que, poco a poco, va cobrando fuerza y consciencia primero como protector de la muchacha y luego, como protector del mundo, contra las tinieblas.

\section{Brona y Lily, un claroscuro}

Otro de los personajes femeninos que dan vida al relato es el de Brona, la prostituta. Ella conoce a Ethan y se enamoran, pero ha contraído tuberculosis. El joven aceptará el trabajo que le ofrece Sir Malcom para comprarle medicamentos. "Brona significa tristeza, en gaélico", afirma la joven. Su nombre se convierte en anticipatorio ya que, ni siquiera el amor será suficiente para evitar su muerte. 
Brona carga con el terrible dolor de haber perdido a su bebé. Para darle de comer, la habría dejado durante unas horas, para prostituirse y conseguir dinero. La pequeña no ha podido resistir la espera y murió víctima del frío y del hambre. Esta culpa corroe su alma.

Acepta un trabajo temporario: sacarse fotos eróticas para Dorian Gray. En medio de la sesión la joven tendrá un acceso de tos y escupirá sangre. Esto excita al hombre, quien mantendrá relaciones con ella y se irá erotizando aún más con la presencia de la sangre y la confirmación de la enfermedad mortal. La cámara alternará entre los planos de la pareja (primeros planos y detalle) y el fotógrafo (plano entero), así como los reflejos en la lente del dispositivo fotográfico (planos detalle). La mente del espectador reconstruirá todos los fragmentos faltantes.

Por su parte, el Dr. Frankenstein tomará el cuerpo sin vida de la prostituta para fabricar la compañera que la creatura le exige, tal como sucedía en el relato de Mary Shelley. Solo que aquí, la serie va más allá: no solo la creará, sino que se enamorará de ella. En la tarea de creación Calibán, la primera creatura a quien Víctor diese vida, oficiará de ayudante en el laboratorio. Brona ha quedado atrás, en la otra vida, de aquí en más será Lily. El rechazo inicial de ella hacia Calibán -su contraparte masculina monstruosa-, proviene indudablemente del film La novia de Frankenstein (1935), de James Whale.

La creación de la fémina y los sentimientos amorosos que el científico despliega hacia ella nos remiten indudablemente al mito de Pigmalión y Galatea. Como el rey de Chipre que había esculpido la estatua de mármol de una bella joven, de la que había quedado prendado, también Víctor se enamorará de su obra. Lily volverá a encontrarse con Dorian Gray, su empleador en su vida pasada y abandonará a Víctor, rompiendo su corazón. Y le advertirá con tono amenazante a su hacedor: "Cuando nos llegue el día, vas a conocer el terror". Es curioso, la serie reduplica e invierte el rechazo. Tal como mencionamos, la creatura (Calibán) ha sido rechazada por su creador, motivo por el cual le ha exigido que le otorgue una compañera. Víctor ha accedido a la petición dándole vida artificial a Lily, pero esta terminará por rechazarlo. Frente a ello, Víctor no se dará por vencido y conseguirá la ayuda de Dr. Jekyll, un antiguo compañero, para continuar sus experimentos, solo que ahora intentará aplacar el mal de la mente de Lily, ya que Jekyll se especializa en este campo. Juntos trabajarán con drogas y electroshocks, en pro de la cura de su amada. Sin embargo, cuando esto sea factible, Víctor tratará de hacerlo a la fuerza. Lily resistirá y le rogará que no le quite el único recuerdo que la aviva: el amor hacia su hija muerta.

Dorian y Lily aparecen como dos seres inmortales que viven la vida al límite dado que no tienen nada que perder. Juntos asisten a una sesión muy especial. En un recóndito sitio de Londres, un grupo de hombres de la alta sociedad se ubican sentados en círculo para presenciar un espectáculo, por el que han pagado. La única presencia femenina es la de Lily, sentada junto a Dorian. Los hombres fuman habanos y visten de etiqueta. Un verdugo ingresa al centro trayendo a una joven desnuda, con los ojos vendados y maniatada. El captor le quita la venda de los ojos y la golpea haciéndola caer. Un plano detalle nos muestra al dominador eligiendo instrumentos de tortura. Un plano detalle nos muestra que se inclina por el látigo. La música que acompaña la escena crea un clima de suspenso creciente, cuando se apronta a comenzar, observamos la cara de satisfacción de los presentes. Dorian y Lily sorprenden a los espectadores y al oficiante, disparándoles y acuchillán- 
dolos. Concluida la faena la mujer le indica a la jovencita temerosa que yace arrodillada a sus pies: "Ahora me perteneces". La pareja lleva a la muchacha, Justine, a vivir con ellos. El diálogo de bienvenida de la mujer es contundente:

Lily: - Los hombres de tu pasado, los que te usaron, los monstruos... ¿Les tienes miedo?

Justine: - ¿Hará que los perdone?

Lily: - No, claro que no. No los perdonarás. No, querida. ¡Tendremos una venganza monumental!

Al tiempo que Lily en los labios a Justine, lo que anticipa el tipo de vínculo que las unirá. La venganza guiará su accionar, aprontándose para lo que está por venir:

Lily: - ¿Cómo crees tú que se logra algo en esta vida? Con destreza, con sigilo, con aplomo. Cortando sigilosamente la garganta al final de la noche. Con la cuidadosa y silenciosa acumulación de poder.

Justine: - ¿Y cuándo tienes ese poder?

Lily: - ¿Qué harías tú con ese poder? ¡Vas a la guerra!

Dorian le entregará a Justine al hombre que la compró a los doce años y luego la prostituyó y vendió a los marineros, a los chinos y a los hombres de Alaska, el mismo que les ha cobrado veinte libras -diez a cada uno- para ver cómo la asesinaban. Maniatado y desnudo, el hombre tiembla en una silla al tiempo que Dorian le da a la muchacha un estilete para que decida qué hacer, advirtiéndole que si decide matarlo no habrá vuelta atrás. La muchacha corta el cuello de su proxeneta y en un arrebato de ira lo apuñalará reiteradas veces. Desnudos y empapados de sangre el trío protagonizará una escena de alto contenido erótico en la que predomina el rojo, que tiñe totalmente sus cuerpos. El diálogo resulta esclarecedor:

Lily: - Construiremos un imperio.

Dorian: - Prostitutas y mujeres deshonradas.

L: - Las desgraciadas y desamparadas.

D: - Las desvalidas.

L: Todas ellas, las mujeres invisibles que pasan desapercibidas en la gran ciudad. Nuestras aliadas.

Justine: - ¿Y luego?

D: - Poder.

L: - No más esclavitud.

D: - Revolución.

L: - Libertad. Y la Libertad es una perra que yace sobre un colchón de cadáveres.

Formarán un ejército de prostitutas que tendrán su punto de reunión en la mansión Gray. Hasta que, finalmente, en una suerte de bacanal sangrienta matarán a quienes las deshonraron, prostituyeron, violaron o vendieron. La casa se convertirá en un sepulcro sangriento. 


\section{Las otras mujeres}

Si bien nos hemos centrado en dos de los personajes femeninos de la serie, Vanessa y Lily, ellas no son las únicas. Mencionaremos algunas de las que aparecen a lo largo de los episodios.

Una de ellas es Angelique, un travesti amante de Dorian Gray, quien comparte momentos de intimidad con el inmortal personaje. Angelique es víctima del rechazo social, podemos ver algunas caras de reprobación al moverse en el círculo social de la alta sociedad, al cual lo lleva Dorian con el afán de escandalizar.

Otro personaje emblemático lo constituye Madame Kali ${ }^{6}$, quien presidirá la sesión de espiritismo durante la primera temporada de la serie. Durante la segunda, Evelyn Poole (Mme. Kali es el nombre con el que se presenta en la sesión de espiritismo) seducirá y embrujará a Sir Malcom. Descubriremos después que en realidad es líder de un viejo aquelarre en el que su hija, Hécate ${ }^{7}$ tiene reservado un importante desempeño. La madre y sus hijas han vendido su alma al diablo, pero las luchas por el poder y quién lidera el aquelarre comprometen la solidez del grupo, que buscará a través de M. Murray llegar y alcanzar a Vanessa. También podremos inquirir que la responsable en última instancia de la muerte de Joan Clayton ha sido su hermana, Evelyn, quien ha complotado en su contra para que la acusen de brujería.

Será Hécate quien intente ganar la adhesión de Ethan a las legiones del Mal. Pese a la ayuda de la bruja, no se torcerán los designios del noble corazón del pistolero, quien terminará asumiéndose como el Lupus Dei, es decir, el Lobo de Dios, defensor de la luz y protector de Vanessa.

La Dra. Seward, constituye un interesante personaje. Una mujer dura, con cabello corto e indumentaria formal; asume un conocimiento en el campo de los estudios del psicoanálisis, en vías de expansión, por medio de sus sesiones. Ella será quien hipnotice a su paciente para que recupere los recuerdos de la época de confinamiento en la Clínica Psiquiátrica del Dr. Banning. Escéptica al principio, irá descubriendo un mundo ignoto y aterrorizante. Tal como le señala Vanessa, ella es igual a quien fuese su mentora Joan Clayton, que muriese quemada en la hoguera por brujería, a lo que la doctora señala que se trata de una rama de su familia, una antepasada. Sin embargo, el primer plano de la cámara parece captar en su rostro un pequeño gesto, que inevitablemente nos lleva a preguntarnos ${ }_{i}$ No se tratará acaso la misma persona? ¿Podría ser posible? Cada uno de los espectadores sacará sus propias conclusiones.

Joan Clayton, conocida como "La abortera del Páramo de Belantry", fue quien le ha enseñado a Vanessa sus conocimientos de hierbas, de invocaciones y de brujería. Perteneciente al antiguo aquelarre de Mme. Kali, enfrentará a esta y a dos de sus hijas para proteger a su aprendiz. Si bien su dureza será chocante en un primer momento, nos enteraremos por momentos de diálogo profundo que Joan ha sido marcada a fuego en su espalda por su hermana y que la aprendiz de bruja ha presenciado situaciones de adulterio en su niñez, cada vez que su madre traía un nuevo amante, lo que la marcó profundamente. Poco a poco entablan una relación afectuosa, la joven ayudará a la mujer mayor, pero no podrá evitar su final trágico. 


\section{Palabras finales}

Narrar una historia de modo audiovisual implica la elección y cambio de los puntos de vista narrativos, lo cual dinamiza la diégesis. En el caso del flashback en el que Vanessa le narra a su amiga que ha escuchado una voz que le ha respondido, como espectadores manejamos la misma cantidad de información que el personaje, es decir, escuchamos junto con ella. No hay nadie más en la habitación. Creemos a pie juntillas que se trata del demonio. Por ello, consideramos que esto es clave para que el personaje no pierda ni la credibilidad ni la simpatía del espectador, ya que nos apiadamos de ella en lugar de censurarla. Comprendemos que el motivo de la traición no es un acto de maldad fraguado por ella, sino el designio de una fuerza oscura. Entendemos además que el hecho que ella acariciase las alas y mostrase su identificación con el ave de rapiña que ha disecado, refuerza intrínsecamente las características que presenta su personaje.

En el caso de Lily, nos compadecemos de ella, ya que nos enteramos que en su vida anterior, Brona fue vendida y prostituida desde joven, pero carga la terrible culpa de haber sido la responsable de la muerte de su bebé. Este dato no es menor, ya que desplaza la empatía del espectador que no justifica pero comprende sí su accionar.

Como podemos ver, todas las mujeres que hemos mencionado, no alcanzan la profundidad y desarrollo de los dos personajes que hemos descripto en profundidad, Vanessa y Lily.

Los años en los cuales se ubica la acción han visto la tarea de las sufragistas y su lucha por el voto femenino. Esto aparece brevemente en uno de los episodios. La propuesta extrema del planteo narrativo lleva a pensar en un ejército de mujeres: prostitutas, deshonradas y marginadas que claman por venganza y llevarán a cabo una sanguinaria gesta.

Martín-Barbero señalaba al definir los personajes que componen el melodrama:

La Víctima es la heroína: encarnación de la inocencia y la virtud, casi siempre mujer. Anota Frye que "el ethos romántico considera el heroísmo cada vez más en términos de sufrimiento, de aguante y paciencia. [...] Es también el ethos del mito cristiano. Este cambio de la concepción del heroísmo explica en gran parte la preeminencia de personajes femeninos en el romanticismo". (1993, p.129)

Si bien es cierto que no se trata de un melodrama, conserva en cierta medida algunas características que nos hacen pensar en la estructura maniquea de este género, donde también podríamos ubicar la figura el villano, como aquel seductor que fascina a la heroína y termina traicionándola -pensamos pues en la presencia del Dr. Alexander Sweet, que es en realidad Drácula- y la presencia del héroe, que nuevamente en este caso identificamos plenamente con el arco de desarrollo recorrido por el personaje de Ethan Chandler que encarna al Lupus Dei -Lobo de Dios-.

Tanto Vanessa como Lily, son mujeres fuertes, guiadas por objetivos diversos. Vanessa busca redimirse hallando a su amiga, a quien ha traicionado la víspera de su boda, con su prometido. Lily busca vengarse de quienes la prostituyeron de joven y luego ha perdido en el camino a su hija. Redención y venganza serán los motores de ambas. Ninguna es la heroína casta y pura ni la villana absoluta, cada una conserva rasgos positivos y negativos, sólo el amor las iguala. 
Al interrogarse acerca de la figura de los malos en las series estadounidenses, Jost (2015) reflexiona acerca del eclipse del sueño americano, para explicar el éxito de los villanos como protagonistas.

Marc Ferro propone la idea de tomar al cine como fuente y agente de la historia para poder leer, a partir de él la misma. Creemos que una lectura similar es la que nos permite interpretar desde las series nuestro tiempo presente.

En nuestro caso, al interrogarnos acerca de los matices que componen a nuestras heroínas y villanas, deberíamos pensar en que el fracaso de las grandes ideologías, el fin de los grandes relatos, la pérdida de valores éticos y morales, la aceleración tecnológica y la globalización, entre tantos otros factores, han socavado nuestros sistemas. La individualización y el aislamiento marcan una nota característica de los tiempos que corren. Hemos perdido nuestros grandes modelos. Las luces de nuestros faros ya no exhiben la luminosidad de antaño. Todo ello indudablemente se refleja en nuestras producciones simbólicas y las series no son la excepción. Tal como señala Forster:

El héroe ha quedado del otro lado de la historia, o, sería mejor decir, al desaparecer de escena y al volverse mera representación espectacular, viene a expresar el fin de la historia entendida como potencialidad y acción. (2011, p. 31).

Se han generado pues cambios, hibridaciones, lo cotidiano y lo íntimo predominan y homogeneizan a los habitantes de este mundo.

Si el cine como medio de masas sirvió para imponer ideologías, modelos, modas y costumbres, valiéndose de estereotipos y clichés, no menos cierto es que en este momento la televisión por cable y las plataformas streaming han tomado el relevo con un alcance global impensable ${ }^{8}$. Es curioso que en un presente en el que nos replanteamos el empoderamiento y el rol de las mujeres, la violencia de género, un tiempo habitado por cuerpos post humanos, aquellos correspondientes a la denominada nueva carne, es decir, los sometidos a operaciones extremas, prótesis y manipulación genética que rozan con lo monstruoso; todos estos temas, de un modo $\mathrm{u}$ otro hallan su correspondencia en los desarrollados en Penny Dreadful. La vida eterna, el mito de la vida artificial, el empoderamiento de la mujer, prácticas sexuales diversas, el goce, la ciencia y el afán del hombre de igualarse a Dios, la maldad. La humanidad no ha inventado nada nuevo en los últimos años, sino que, por el contrario, ha puesto en palabras prácticas diversas y las ha visibilizado. Las producciones artísticas no quedan al margen de esos temas que, con ropajes diversos nos interpelan como espectadores. Las series televisivas no es la excepción, realizar pues una lectura crítica se torna el desafío de nuestro presente.

\section{Ficha técnica}

Logan, John (Dir.), 2014. "Penny Dreadful”. Reino Unido - Irlanda - USA: Showtime, Neal Steet Productions, Desert Wolf Productions, 2014. (Terror. Fantástico color, 3 Temporadas: 27 episodios de 52 m.) Guion: John Logan, Andrew Hinderaker, Krysty Wilson- 
Cairns. Con: Eva Green, Josh Hartnett, Timothy Dalton, Harry Treadaway, Rory Kinnear, Billie Piper, Reeve Carney.

\section{Notas}

1. Penny Dreadful u Horrores de penique era el nombre con que se conocieron los relatos de la época victoriana, caracterizados por la sangre y la truculencia. Este tipo de literatura, de publicación semanal, era consumida por las clases populares. Entre los títulos más conocidos podemos mencionar Sweeney Tood: the Demon Barber of Fleet Street y Barney the Vampire.

2. Katábasis: descenso a los infiernos.

3. Hemos abordado el tópico del mito de la vida artificial en nuestro trabajo Penny Dreadful: entre el los mitos y el terror expuesto en las $50^{\circ}$ Jornadas de Estudios Americanos - AAEA, Universidad Nacional de Mar del Plata, 15 al 17 de noviembre de 2018.

4. William Wordsword (1770-1850) fue uno de los más importantes poetas románticos ingleses. En 1798 realizó una obra conjunta con Samuel Taylor Coleridge, Baladas líricas, obra influyente en la literatura del siglo XIX.

5. William Blake (1757-1827) fue poeta, pintor y grabador inglés, perteneciente al romanticismo. Entre sus obras memorables en literatura figura El casamiento del cielo y la tierra. Es necesario considerar su obra literaria en relación con su actividad plástica para comprender que se trata de un artista total.

6. Kali es una diosa de la mitología hindú. Su nombre provendría del sánscrito antiguo y significa "oscuridad" (también "mujer negra"). Es la esposa de Shiva. Se la representa como salvaje y ligada a la muerte y la destrucción, aunque en una etapa tardía aparece como la Gran Diosa Madre. Iconográficamente se la presenta como una mujer de color con cuatro brazos y un collar compuesto por calaveras.

7. Hécate era en la mitología griega una diosa que no tenía mito propio, tal como refiere Grimal: "se aparece a los magos y a las brujas con una antorcha en la mano o en la forma de distintos animales: yegua, perra, loba, etc. Le es atribuida la invención de la hechicería." Grimal, P. (1997). Diccionario de motología griega y romana. Bs. As.: Paidós.

8. Bástenos recordar que la plataforma Netflix cuenta en la actualidad con 190.000 .000 de abonados en el mundo y proyecta alcanzar los 400.000.000 en los próximos dos años.

\section{Lista de Referencias Bibliográficas}

Calabrese, O. (1994). La era neobarroca. Madrid: Cátedra.

Jost, F. (2015). Los nuevos malos. Cuando las series estadounidenses desplazan las líneas del Bien y del Mal. Bs. As.: Libraria.

Ferro, M. (1995). Historia contemporánea y cine. Barcelona: Ariel.

Ferro, M. (2008). El cine, una visión de la historia. Madrid: Akal.

Forster, R. (2011). La muerte del héroe. Itinerarios críticos. Bs. As.: Ariel.

Foucault, M. (1998). Historia de la locura en la época clásica. Vol. 2. Colombia: FCE. 
Lipovetsky, G., Serroy, J. (2009). La pantalla global. Cultura mediática y cine en la era hipermoderna. Barcelona: Anagrama.

Martín-Barbero, J. (1993). De los medios a las mediaciones. Comunicación, cultura y hegemonía. México: Gustavo Gili.

Sarti, G. (2012). Autómata. El mito de la vida artificial en la literatura y el cine. Bs. As.: Facultad de Filosofia y Letras (UBA).

Shelley, M. W. (2006). Frankenstein o el Prometeo moderno, trad. Ledesma, J.Bs. As.: Coluhue.

\begin{abstract}
The '50s greeted cinema as the king of entertainment. Also, throughout the last century, many voices rose up predicting his death. However, far from disappearing, the screens have multiplied exponentially: cinema, television, smart phones and tablets produce and re-produce the reality that surrounds us. Screens of all kinds: liquid crystal, flat, tactile, graphic, small and giant.It is the height of the "global screen", as Lipovetsky and Serroy (2009) say. We are undoubtedly immersed in the world of the image.

Speed, change and fragmentation characterize our time. Satisfying the demand of the avid consumer of entertainment products has turned into the biggest challenge of the present. In this way, the series produced for television and the various streaming systems strive to become the undisputed emperors. We can affirm then, without fear of making mistakes, that the series are to the media spectator what once the cinema of the golden age was to its audience. In this way, actors, producers and film directors have been tempted to join this field that is in full expansion. From the Internet to the various platforms -Netflix, Qubit TV and the native Cine.ar, among others- through channels with premium packages, the offer is multiplied presenting us with products for the most demanding palates.

We are witnessing a time of great changes: the feminist movements that help to reconsider the role of women, as well as the relations between the sexes in the past and the present, projecting them into the future. Globalization expands, through communications, the scope of these changes to all sectors of the planet; and, given the profusion of television products, it is not surprising that all these transformations are reflected in the media.

Series, as well as other productions, are not left out. Each and every one of them presents themes that are disturbing: the relations between the sexes, the independence of the woman, the bodies -trans, cyber, post human-, to name but a few, nourish the different stories. This work aims to analyze the construction of the female image in the television series: Penny Dreadfull (2014-2016), created by John Logan. This American-British co-production has explored vampirism, the demonic, lycanthropy, artificial life and eternal youth. The first season of the series goes about the search for Mina, the missing daughter of Sir Malcom Murray. For this he will count on Vanessa Ives' help, childhood friend of his offspring. Aided by Ethan Chandler, the faithful African servant Sembene, and Victor Frankenstein. The latter will give life -artificial- to a monstrous progeny: Proteus, of a short life; Caliban, who craving for love will demand a companion; and Lily -a luck of Lilith redived? -. The third season will have the presence of Dracula, who will try to crown Vanessa as the Mother of all evils. In this way, heroines and evil women give life to unsettling females.
\end{abstract}


We are interested in analyzing the various female roles that embody a polarized balance of heroines and evil. We propose to walk the path they travel to reflect on their characteristics, how the character is constructed or deconstructed to find out whether the heroine and the evil one coexist within the same character or they are different characters. Above all, whether the vision about women as it appears on the series corresponds to that of the Victorian era in which the story is set, or it reflects elements of our present seen from a distance. It is like this that we are supposed to read our present from said series production.

Keywords: Female image - Construction - Heroine - Evil - Series - Character - Evolution Changes - Stereotypes - Artificial life

Resumo: Nos anos '50 cumprimentaram ao cinema como o rei do entretenimento; assim mesmo, ao longo do século passado, muitas vozes alçaram-se vaticinando sua morte. No entanto, longe de desaparecer, as telas multiplicaram-se exponencialmente: cinema, televisão, celulares e tablets produzem e re-produzem a realidade que nos rodeia. Ecrãs de todo o tipo: de cristal líquido, planas, táctiles, gráficas, pequenas e gigantes.

Trata-se do apogeo da "tela global", tal como afirma Lipovetsky. Achamos-nos, indubitavelmente, submergidos no mundo da imagem.

A velocidade, a mudança e a fragmentação caracterizam nosso tempo. Satisfazer a demanda do ávido público consumidor de produtos de entretenimento torna-se o maior desafio do presente. Deste modo, as séries produzidas para televisão e os diversos sistemas streaming pugnan por converter nos imperadores indiscutibles. Podemos afirmar pois, sem temor a equivocar-nos, que as séries são ao espectador mediático o que outrora fosse o cinema da idade de ouro a suas audiências. Deste modo, actores, produtores e diretores cinematográficos viram-se tentados a incorporar neste campo que se acha em franca expansão. Desde Internet às diversas plataformas -Netfix, Qubit TV e a autóctona Cinema Ar, entre outras-, passando pelos canais com pacotes premium, a oferta multiplica-se oferecendo produtos para os paladares mais exigentes.

Assistimos neste momento a uma época de grandes mudanças: os movimentos feministas que ajudam a repensar o papel das mulheres, bem como as relações entre sexos no passado e o presente, projectando face ao futuro. A globalização expande, por meio das comunicações, os alcances de ditos mudanças de concepções a todos os sectores do planeta; e, dada a profusão de produtos de televisão, não é de estranhar que todas estas transformações se reflitam nos meios.

As séries como todas as demais produções não ficam à margem. Todas e a cada uma apresentam temas que inquietam: as relações entre sexos, a independência da mulher, os corpos -trans, ciber, pós humanos-, entre outros, nutrem as diferentes histórias.

Este trabalho propõe-se analisar a construção da imagem feminina na série televisiva: Penny Dreadfull (2014-2016), criada por John Logan. Esta coproducción estadounidense-britânica tem explorado o vampirismo, o demoníaco, a licantropía, a vida artificial e a eterna juventude. A primeira temporada da série orienta-se em torno da busca de Mina, a desaparecida filha de Sir Malcom Murray. Para isso contará com a ajuda de Vanessa Ives, amiga da niñez de sua retoño. Ajudados por Ethan Chandler, o fiel servente africano Sem- 
bene, e Víctor Frankenstein. Este último dará vida -artificial- a uma progenie monstruosa: Proteo -de vida esfímera-, Calibán -que ante a falta de amor de hacedor exigir-lhe-á uma colega- e Lily - ¿uma sorte de Lilith rediviva?-. A segunda temporada contará com a presença de Drácula, quem tentará coroar a Vanessa como a Mãe de todos os males. Deste modo, heroínas e malvadas dão vida a inquietantes féminas.

Interessa-nos analisar os diversos papéis femininos que encarnam um equilíbrio polarizado de heroínas e malvadas. Propomos-nos transitar o caminho que percorrem para refletir a respeito de suas características, como se constrói ou de-constrói a personagem para averiguar se a heroína e a malvada convivem ao interior de uma mesma personagem ou se é trata de personagens diferentes, mas por sobretudo, se a visão sobre as mulheres que aparece na série corresponde à da época victoriana na qual se acha ambientado o relato, ou se reflete elementos de nosso presente distanciados temporariamente. É assim, que supomos poder ler nosso presente a partir de dita produção serial.

Palavras chave: Imagem feminina - Construção - Heroína - Malvada - Série - Personagem - Evolução - Mudanças - Estereótipos - Vida artificial

[Las traducciones de los abstracts fueron supervisadas por el autor de cada artículo] 